\title{
CRÍTICA AO FINANCIAMENTO DA EDUCAÇÃO PÚBLICA NO BRASIL SOB A PERSPECTIVA MARXISTA
}

\author{
CRÍTICA AL FINANCIAMIENTO DE LA EDUCACIÓN PÚBLICA EN BRASIL BAJO LA \\ PERSPECTIVA MARXISTA
}

\section{CRITICAL TO THE FUNDING OF PUBLIC EDUCATION IN BRAZIL FROM THE PERSPECTIVE OF MARXIST}

DOI: $\underline{\text { http://dx.doi.org/10.9771/gmed.v11i2.32919 }}$

\section{Fábio Araujo de Souza ${ }^{1}$}

Resumo: Este artigo objetiva analisar, sob a perspectiva do materialismo histórico e do materialismo dialético, o financiamento da educação pública no Brasil. A influência dos EUA, através dos órgãos multilaterais tais como o FMI, o BM, o BID, entre outros, tem condicionado as políticas educacionais para o financiamento da educação pública no Brasil há décadas. Os efeitos mais intensos têm sido a forte presença do setor privado e os desinvestimentos na área. É importante analisar o financiamento da educação para além da sua pseudoconcreticidade e assim esgotar as determinações desse objeto com a finalidade de revelar como realmente as políticas de financiamento da educação têm se estruturado.

Palavras-chave: financiamento da educação, marxismo, política educacional.

Resumen: Este artículo tiene como objetivo analizar, desde la perspectiva del materialismo histórico y el materialismo dialéctico, el financiamiento de la educación pública en Brasil. La influencia de Estados Unidos a través de agencias multilaterales como el FMI, el BM, el BID, entre otros, ha condicionado las políticas educativas para el financiamiento de la educación pública en Brasil durante décadas. Los efectos más intensos han sido la fuerte presencia del sector privado y las desinversiones en el área. Es importante analizar la financiación de la educación más allá de su pseudoconcreticidad y, por lo tanto, agotar las determinaciones de este objeto para revelar cómo se han estructurado realmente las políticas de financiación de la educación.

Palabras clave: financiamiento de la educación, marxismo, política educativa.

Abstract: This article aims to analyze, from the perspective of historical materialism and dialectical materialism, the financing of public education in Brazil. US influence through multilateral agencies such as the IMF, WB, IDB, among others, has conditioned educational policies for the financing of public education in Brazil for decades. The most intense effects have been the strong presence of the private sector and divestments in the area. It is important to analyze education funding beyond its pseudoconcreticity and thus to exhaust the determinations of this object in order to reveal how education financing policies have actually been structured.

Keywords: education financing, Marxism, educational policy.

\section{Aproximações epistemológicas}

Antes de analisar os direitos sociais na sociedade de classes, é importante fazer uma discussão teórica sobre o trabalho, especificamente, o trabalho humano. Para Karl Marx (1818-1883), o trabalho fundamenta a ação humana, portanto, é uma atividade vital (MARX, 1844) e, por ser consciente, é livre, permitindo ao homem produzir universalmente. Marx (1844, s/p) afirma que o 
objetivo do trabalho, portanto, é a objetificação da vida como espécie do homem, pois ele não mais se reproduz a si mesmo apenas intelectualmente, como na consciência, mas ativamente e em sentido real, e vê seu próprio reflexo em um mundo por ele construído (Marx, 1844, s/p).

Contudo, Marx afirma que, com o advento da sociedade moderna, com base no sistema econômico capitalista, o trabalho ou a "força de trabalho" (conceito que Marx e Engels dão centralidade em suas análises) é transformada em mercadoria. Dessa forma, deixa de ser atividade livre para se tornar trabalho alienado, em que "o trabalhador frequentemente não se satisfaz no trabalho, mas se degrada; não se reconhece, mas muita das vezes recusa e se desumaniza no trabalho" (ANTUNES, 2013, p. 9).

A força de trabalho torna-se mercadoria e sua finalidade na sociedade capitalista é sumariamente criar novas mercadorias e valorizar o capital. No processo de produção e de valorização da mercadoria, tornam-se centrais a diminuição do tempo de trabalho socialmente necessário e o aumento da mais-valia ou lucro. Assim, o capitalista se empenha em: pagar menor valor pela força de trabalho comprada (trabalho assalariado); aumentar a jornada de trabalho para além do tempo de trabalho necessário para a existência do trabalhador; e aumentar a intensidade do trabalho. Contudo, o capitalista encontra dificuldades para explorar e expropriar plenamente a força de trabalho pela reação dos trabalhadores, sobretudo, através do sindicato - que para Marx atuam como centros de resistência contra as usurpações do capital - que tensiona o Estado a regulamentar direitos para a classe trabalhadora.

Uma categoria importante nesse momento se refere a do Estado moderno ou Estado capitalista. Para o filósofo alemão Max Weber (1864-1920), é a "relação de dominação de homens sobre homens", na qual os dominados submetem-se à autoridade imposta pelos dominantes (WEBER, 1999, p. 526). A visão do autor expressa o papel fundamental da violência e da força para a dominação legítima, portanto, reconhecida pelos dominados. Esse conceito de Estado moderno é deveras determinista e expressa claramente o ideal de Estado, logo não colabora para entender as tessituras da realidade social e material.

No Manifesto do Partido Comunista, Marx e Engels formulam o conceito de que o Estado moderno nada mais é do que um comitê para a administração dos assuntos comuns de toda a burguesia. O Estado, para os autores, é uma instituição concreta separada do resto da sociedade e sobreposta à sociedade. Para Engels (2010), a burguesia defende seus interesses por meio do poder estatal, o que denota que uma função inexorável do Estado é funcionar como uma agência de negócios da burguesia cuja função principal é defender os interesses dessa classe.

Para Poulantzas (1980), uma teoria geral do Estado incorre em uma generalização abstrata e trans-histórica a qualquer sociedade, por isso, assim como Marx, detém suas análises a uma teoria do Estado capitalista, mais precisamente a "teoria relacional do Estado". É importante lembrar que Poulantzas não se afasta do conceito marxista do Estado capitalista; pelo contrário, aproxima-se e aprofunda as análises.

Poulantzas entende que o próprio processo de organização do Estado é parte constitutiva do estabelecimento de relações de produção capitalistas como processo histórico específico que constitui as lutas de classes. Entender o Estado como relação permite compreender que, no tocante às classes dominantes, consideradas como unidade conflitual entre classes e frações de classes, o Estado representa 
os interesses políticos a longo prazo dessa classe ou fração hegemônica, sem, porém, eliminar as contradições que permeiam as relações entre as classes e as frações dominantes.

Dessa forma, a política de Estado pode parecer incoerente e caótica, mas constitui a materialização do processo efetivo de contradições internas, configurando-o como lugar de organização estratégica da classe dominante. O nível de correlação de forças em cada formação social concreta e em cada conjuntura específica indica o grau de contradição presente na organização interna do Estado. Assim, segundo Poulantzas (1980, p. 167), "as lutas populares estão inscritas na materialidade institucional do Estado, mesmo se não se esgotam aí".

Fica nítido que a luta dos trabalhadores por direitos arrefece o processo antagônico de exploração e expropriação que marca a relação da classe dominante com a dominada. Nesse sentido a mobilização dos trabalhadores e a organização dos mesmos, através de sindicatos, são fundamentais para o tensionamento por direitos trabalhistas. Contudo, as ações e contra-ações da classe dominante tendem a impedir a conquista de direitos dos trabalhadores, ou mesmo, desregulamentar importantes conquistas para assegurar o lucro dos capitalistas e sua ação hegemônica sobre a classe dominada. A luta da classeque-vive-do-trabalho (ANTUNES, 2013), através dos movimentos sociais e dos sindicatos é fundamental para o equilíbrio das relações entre trabalhadores e empregadores, haja vista que a tendência geral da produção capitalista não é aumentar, mas reduzir as conquistas dos trabalhadores.

As atuais contrarreformas da previdência, do trabalho, da educação e de outras áreas sociais comprovam essa desregulamentação das leis que asseguram direitos sociais no país. Para Coutinho (2012, p. 124), o "que caracteriza um processo de contra-reforma não é assim a completa ausência do novo, mas a enorme preponderância da conservação (ou mesmo da restauração) em face das eventuais e tímidas novidades". As contrarreformas expressam a preponderância do sistema econômico capitalista em relação às históricas conquistas da classe trabalhadora. Nesse sentido os governos incumbem-se de manter a ordem social (repressivamente e ideologicamente), utilizando Dispositivos Repressivos do Estado e Aparelhos Ideológicos do Estado (ALTHUSSER, 1970). É importante destacar que corroborando com essa disputa a mídia tem papel estratégico na defesa dos interesses da classe dominante ao defender as contrarreformas que também são de seu interesse nessa "guerra de posição no terreno político" (GRAMSCI, 1988).

Dentro desse processo a educação, sobretudo a pública, exerce papel fundamental, seja para manutenção do status quo social, através da consolidação da hegemonia cultural, seja através da exploração e da expropriação da força de trabalho dos profissionais da educação. Para entender essa dinâmica, é importante analisar como se configuraram as principais políticas, de modo sintetizado, da educação sob a perspectiva do materialismo histórico e dialético.

\section{Principais aspectos históricos críticos da garantia do direito à educação através do financiamento}

A escola pública é uma instituição típica da sociedade moderna e se constituiu como uma instituição necessária para a consolidação do status quo na sociedade capitalista moderna. No Brasil, em 
1759, através do Alvará Régio, de 28 de junho, a Companhia de Jesus foi expulsa de Portugal e de todas as suas colônias pelo primeiro-ministro do Reino, Marquês de Pombal, no império de Dom José I. A medida tinha como objetivos: organizar a administração a fim de avançar nos progressos industriais da Coroa; dissipar os conflitos entre os colonos e os jesuítas acerca da escravização dos nativos; e romper o fortalecimento econômico que a Companhia de Jesus estava obtendo com suas 36 missões. Baseado nos princípios iluministas, o Marquês concebia a educação pública como instrumento ideológico e, portanto, capaz de dominar e dirimir a ignorância que grassava na sociedade, condição incompatível e inconciliável com as ideias iluministas (SANTOS, 1982).

O marquês de Pombal criou, em 1772, o subsídio literário para financiar as aulas régias na metrópole e nas colônias, o que demonstrava sua vontade de estatizar o ensino. O imposto criado incidia sobre a venda e produção da carne, da aguardente, do sal e do vinagre. Contudo, como afirma Cury (2018, p. 1220): "A situação de precariedade com que eram cobrados tais subsídios sobre a carne verde, os vinhos portugueses, a aguardente, o sal e o vinagre não permitiu a subvenção regular e permanente dessa primeira tentativa de criação de uma rede pública de ensino”. Durante o império nenhuma outra fonte significativa de recursos para a educação foi criada.

Com a independência do Brasil, a Constituição Imperial de 1824 no artigo 172 previa que os recursos gerais da educação saíssem dos orçamentos estaduais. A gratuidade do ensino primário a todos os cidadãos estava prevista na primeira constituição brasileira, porém o índio e o negro não figuravam como cidadãos e os analfabetos e as mulheres não eram plenamente cidadãos, no que se refere à participação política, pois não tinham direito ao voto (VIEIRA, 2007). A Lei Geral da Educação, em 1827, também, foi inócua em relação à fonte de recursos consistente para financiar o ensino.

O Ato Adicional de 1834 determinava a descentralização do ensino primário para as Províncias, com isso criou-se um dualismo de redes escolares em que os impostos mais importantes estavam sob a égide dos poderes gerais centrais. Em 1879, a Reforma de Leôncio de Carvalho tratou da subvenção do governo às instituições de beneficência com a finalidade de desenvolver e propagar a instrução pública. E criou legalmente as Caixas Escolares que tinham um papel fundamental para estimular a frequência e combater a evasão dos alunos pobres nas escolas nesse período.

A primeira Constituição republicana se silenciou sobre a gratuidade da instrução primária para todos, como previa a Constituição imperial. As mulheres, os índios, os negros - mesmo após a Lei Áurea - e os analfabetos não eram considerados cidadãos e, portanto, não podiam votar. A preocupação com a educação pública materializou-se com as Reformas de Benjamin Constant, que tinham uma base epistemológica baseada no positivismo e eram de cunho liberal e elitista. As reformas abrangeram o ensino primário e secundário do Distrito Federal, o Ginásio Nacional (Decretos 981/90 e 1.075/90, respectivamente) e o Conselho de Instrução Superior (Decreto 1.232-G/91).

No campo do financiamento, o ensino primário ficou a cargo dos Estados, ou seja, no primeiro período republicano, ou República Velha, não se alterou em relação ao período imperial. Algumas medidas incipientes sobre as fontes de recursos para o ensino marcaram esse período: criação do Imposto de Renda; recursos programados das taxas do ensino superior pagos pelos estudantes; impostos sobre 
bebidas alcoólicas para a caridade; contribuições para instrução popular em razão de assistência e proteção oferecidas por instituições beneficentes; e o subsídio parcial da União para pagamento do salário dos professores rurais (CURY, 2018).

A remodelação do sistema econômico capitalista foi necessária para a saída da crise de 1929; os Estados Unidos adotaram os antídotos Keynesianos e aos poucos conseguiram estabilizar o quadro agudo no qual a economia se encontrava. A crise internacional ensejou limites às importações pelo Brasil e isso culminou no fortalecimento de setores da indústria brasileira. O desenvolvimentismo brasileiro, promovido num processo endógeno de industrialização, apresentou prontamente a necessidade de promover a educação pública, gratuita e laica no país.

Nesse sentido, a Revolução de 1930, comandada por Getúlio Vargas, culminou no golpe que depôs o presidente Washington Luís, rompendo com a política do "café com leite", e proporcionou a Assembleia Constituinte e a promulgação da Constituição Federal (CF) de 1934, que trouxe significativos avanços para a educação nacional ao vincular percentuais de recursos mínimos para o ensino, obrigatoriamente, para todos os entes federados. Uma das primeiras medidas de Vargas foi a criação do Ministério dos Negócios da Educação e Saúde Pública através do Decreto 19.402/1930. Os princípios liberais acerca da defesa da escola pública, gratuita e laica defendidos pelos Pioneiros da Educação Nova ganhavam terreno fértil nesse momento histórico.

No campo do financiamento da educação, os pioneiros, através de um manifesto, cujos signatários eram representantes das elites do país, previam um fundo específico para financiar a educação pública, criado em 1932 pelo Decreto 21.335, cujos recursos seriam oriundos da cobrança de taxa sobre documentos sujeitos a selo federal, estadual ou municipal. Em 1934, com a promulgação da Constituição, a União e os municípios deveriam aplicar $10 \%$ e os estados e o Distrito Federal (DF) 20\%, no mínimo, das receitas resultantes de impostos na Manutenção e Desenvolvimento do Ensino (MDE). Além disso, a União teria uma ação supletiva (que de fato foi cumprida pela Lei 378, que determinava a construção e manutenção de escolas primárias e profissionais em zonas rurais); os entes deveriam constituir seus fundos de educação e deveria ser criado pelo Conselho Nacional de Educação (CNE) um Plano Nacional de Educação (PNE) (que chegou a ser elaborado pelo CNE).

Contudo, as medidas apresentadas pela Constituição de 1934 não seguiram adiante devido à instauração do regime autoritário com traços fascistas do Estado Novo, que, em 1937, teve uma Constituição outorgada pela ditadura Vargas. Esta retroagiu bastante no que se refere aos direitos à educação pública, inclusive, através da não previsão da vinculação constitucional de recursos mínimos para o ensino do novo texto constitucional. Em 1941, foi realizada a $1^{\text {a }}$ Conferência Nacional de Educação, que apontou a necessidade de retornar com a vinculação de recursos mínimos para o ensino, sobretudo, pelos péssimos índices educacionais.

Em 12 de novembro de 1942, foi aprovada a Lei 4.958, que instituiu o Fundo Nacional do Ensino Primário, efetivado somente 6 anos depois (CURY, 2018, p. 1228). Sob o Estado Novo foram criados decretos-leis referentes ao ensino industrial (Lei Orgânica do Ensino Industrial - Decreto-lei 4.073/42), ao secundário (Lei Orgânica do Ensino Secundário - Decreto-lei 4.244/42) e ao comercial (Lei 
Orgânica do Ensino Comercial - Decreto-lei 6.141/43). Também durante esse período foi criado o Serviço Nacional de Aprendizagem Industrial (Senai - Decreto-lei 4.048/42) (VIEIRA, 2007).

Com o fim da Segunda Guerra (1939-1945), não era necessário para os EUA manter o Estado Novo. Além disso, "o Brasil necessitava de capitais externos para dar continuidade ao seu processo de industrialização e, novamente, seria conveniente ao governo brasileiro demonstrar que os ventos democráticos também sopravam por aqui” (MUNHOZ, 2002, p. 46). Em 1945, terminou a ditadura varguista e ocorreu a reabertura política. Um ano depois foi promulgada uma nova Constituição Federal, que determinou os percentuais mínimos de recursos no ensino para os entes federados e estabeleceu que a União deveria aplicar 10\% e estados, municípios e DF nunca menos de $20 \%$ das receitas resultantes de impostos na MDE e, ainda, tratava da criação de um Fundo Nacional para o ensino primário e da criação da Lei de Diretrizes e Bases da Educação Nacional (LDB).

Em 1948, o ministro da educação e da Saúde do governo Dutra enviou ao Congresso o projeto de LDB e, somente em 1957, o projeto entrou na ordem do dia junto com outro projeto apresentado por Carlos Lacerda. Após intensos debates entre os defensores da educação pública, gratuita e laica e os privatistas, foi aprovado um projeto com fortes traços privatistas (Lei federal 4.024/1961). O PNE se concretizou, em 1962, com metas audaciosas para a educação nacional.

A LDB previa que a União aplicasse 12\%, e os estados, DF e municípios 20\% da receita resultante de impostos na MDE, ou seja, a lei aumentou o percentual previsto na CF/46 para a União e manteve o percentual dos demais entes. Contudo, cabe destacar que, por se tratar de uma lei federal, não poderia se sobrepor ao que determinava a $\mathrm{CF}$, portanto, a União não seria obrigada a cumprir o percentual.

Com a intensificação dos conflitos internacionais oriundos da Guerra Fria, novamente, o país foi acometido por uma ditadura. A presidência foi dada como vaga às 3 horas da manhã pelo presidente do Congresso, com aval do Supremo Tribunal Federal, mesmo com o presidente da República estando em território brasileiro (BALEEIRO, 1968). Com a instauração da ditadura, as mudanças na educação foram intensas. A nova Constituição (proclamada por um Congresso subserviente), em 1967, não previa a vinculação de percentual mínimo para o ensino. As políticas educacionais propostas pelos civis no período da ditadura basearam-se no tecnicismo e no privatismo, sobretudo, através dos acordos do Ministério da Educação (MEC) com a Agência dos Estados Unidos para o Desenvolvimento Internacional, mais conhecida por seu acrônimo em inglês USAID (CUNHA, 2014).

Uma das primeiras medidas para a educação foi criar o Salário-Educação (SE), cuja fonte de receita vinha da contribuição social que incidia sobre a folha de pagamento das empresas. Os recursos deveriam financiar o ensino primário, mas acabaram indo para o ensino privado, pois a lei permitia que as empresas criassem sua própria escola ou comprassem bolsas nas escolas privadas. Ainda, foram constatadas diversas fraudes com o uso dos recursos do SE através da cobrança aos alunos de valores para complementar as bolsas oferecidas; pagamento de bolsas para alunos fantasmas; de superfaturamento das bolsas; entre outras (DAVIES, 2009). 
Os ministros civis do MEC modificaram a LDB através de duas reformas: 1) pela Lei federal 5.540/1968, que fixou normas de organização e funcionamento do ensino superior, tornando mais eficiente o controle de qualquer manifestação contrária à ditadura civil-militar; 2) pela Lei federal 5.692, de 11 de agosto de 1971, que alterou o ensino primário e secundário, inclusive nomeando-os de $1^{\circ}$ e $2^{\circ}$ graus, respectivamente.

A reforma aumentou a obrigatoriedade do ensino de 4 para 8 anos (dos 7 aos 14 anos de idade), porém, no que se refere ao financiamento, determinava apenas para os municípios a aplicação de pelo menos 20\% da receita tributária e 20\% do Fundo de Participação dos Municípios para o ensino de $1^{\circ}$ grau. Também previa recursos para a privatização do ensino através do amparo financeiro do setor público às instituições privadas, a aquisição pelo poder público de bolsas de estudos nas escolas privadas.

Em 1968, foi criado o Fundo Nacional de Desenvolvimento da Educação (FNDE), a fim de reunir recursos financeiros governamentais de diversas fontes e canalizá-los para o financiamento de projetos de ensino para os governos estaduais, distrital, municipais, bem como para as instituições privadas. Em 1969, os ditadores outorgaram a Emenda Constitucional 01, que determinou a intervenção dos Estados nos municípios que não aplicassem, pelo menos, $20 \%$ da receita tributária no ensino primário.

Contudo, a complexidade dos entraves educacionais não seria resolvida com a obrigatoriedade do financiamento da educação somente para os municípios. O senador João Calmon apresentou, em julho de 1976, uma proposta de emenda à Constituição que visava restabelecer a vinculação de percentual mínimo da receita da União em $12 \%$ e dos estados, DF e municípios 24\%, pelo menos, à expansão e ao aprimoramento do ensino. Mas a proposta foi rejeitada por decurso do prazo.

Em 1983, a emenda apresentada novamente pelo senador foi aprovada determinando que a União aplicasse, pelo menos, $13 \%$ e os estados, DF e municípios 25\%, no mínimo, da receita resultante de impostos na MDE. Para regulamentar a EC 24/83, foi aprovada a Lei federal 7.348/1985, que, entre outras coisas, detalha as despesas que podem e não podem ser consideradas MDE. Com o fim da "Guerra Fria", não havia mais necessidade de manter a ditadura civil-militar no país e, em consequência da reabertura política, iniciou-se um processo de discussão da nova Constituição Federal.

A participação do senador João Calmon e do Fórum Nacional de Defesa da Escola Pública (FNDEP) foi fundamental para a garantia do percentual mínimo de recursos para MDE na Carta de 1988. No final da ditadura civil-militar, as despesas com educação dos governos federal, estaduais e municipais representavam apenas 2,72\% do Produto Interno Bruto (PIB), segundo o Instituto Brasileiro de Geografia e Estatística (IBGE) (MELCHIOR, 1987).

\section{Educação pós-abertura política: avanços e retrocessos}

A CF/88 é a mais extensa de todas em relação aos dispositivos da educação: são 10 artigos específicos, 4 dispositivos no corpo do texto e 2 nos Atos das Disposições Constitucionais Transitórias. Alguns pontos de destaque da CF/88 sobre a educação determinam: a educação como dever do estado e 
da família e direito de todos; a gestão democrática do ensino público; a autonomia administrativa e de gestão financeira e patrimonial didático-científica das universidades; o atendimento educacional especializado aos portadores de deficiência, preferencialmente, na rede regular de ensino; o acesso ao ensino obrigatório e gratuito como direito público subjetivo; a função redistributiva e supletiva da União mediante assistência técnica e financeira aos entes federados; o financiamento da educação através da aplicação de $18 \%$ da União e $25 \%$ dos estados, DF e municípios, no mínimo, da receita resultante de impostos na MDE.

Os avanços conquistados na $\mathrm{CF} / 88$ logo foram frustrados pelos retrocessos impostos pela política de acumulação capitalista de cunho neoliberal que chegavam ao país, mais intensamente via Consenso de Washington cujo objetivo era determinar 10 medidas econômicas para os países da AméricaLatina no sentido de promoverem o ajustamento macroeconômico através do ideário neoliberal. $\mathrm{Na}$ educação, a Conferência Mundial de Educação para Todos, em 1990, ocorrida, em Jomtien, na Tailândia, traçou as regulamentações que os países em desenvolvimento deveriam seguir, sobretudo, aqueles países com altos índices de analfabetismo, entre eles, o Brasil.

A Conferência inspirou o governo de Itamar Franco a criar o Plano Decenal de Educação para Todos, em 1993. Segundo o próprio MEC, esse Plano não era o que estava previsto na CF/88, mas, sim, visava a "eliminar o analfabetismo e universalizar o ensino fundamental" nos próximos dez anos (MEC, 1993) e não passou de ações desarticuladas do governo Itamar, pouco avançando no desenvolvimento das políticas nacionais para educação. Também, no governo Itamar, foi criado o Fundo Social de Emergência (FSE) cujo objetivo era desvincular 20\% das receitas da União para estabilizar a economia logo após o Plano Real.

Entre as políticas adotadas nos dois mandatos de FHC (1994-1997/1998-2002), destacam-se a aprovação da LDB (Lei federal 9.394/1996), a promulgação da EC 14/1996, que, entre outras medidas, criou o Fundo de Manutenção e Desenvolvimento do Ensino Fundamental e de Valorização dos Profissionais do Magistério (Fundef), a aprovação do PNE (Lei federal 10.172/2001) e o fortalecimento dos programas de descentralização de recursos para as unidades escolares via associações privadas.

A tramitação dos projetos de LDB/1996 durou 8 anos no Congresso. De um lado, um anteprojeto elaborado pelo FNDEP através dos encontros nacionais com a participação da sociedade; do outro, o projeto dos tecnocratas do MEC e dos privatistas. Após anos de embates, discussões, debates, disputas, tramas, conluios e tramoias legislativas, sobretudo por parte do senador Darcy Ribeiro, o projeto apresentado pelo MEC foi aprovado com poucas alterações.

Apesar desse controverso caminho na tramitação, a LDB/1996, no que se refere ao financiamento da educação, apresenta alguns pontos positivos, como: permitir que o percentual mínimo das Constituições Estaduais e Leis Orgânicas fosse considerado quando acima do percentual previsto na $\mathrm{CF} / 88$; determinar que os recursos para a MDE sejam aplicados no setor público; prever que as diferenças entre a receita e a despesa previstas e as efetivamente realizadas sejam corrigidas trimestralmente; e definir as despesas que podem ou não ser utilizadas com recursos da MDE. 
A tramitação do PNE/2001 também foi baseada em “tramoias” e movimentações no Congresso para enfraquecer o projeto apresentado pela sociedade. Contudo, o texto final apresentou alguns avanços como prever a aplicação do correspondente a 8\% do PIB na educação. Porém, essa e outras metas referentes ao financiamento foram vetadas pelo presidente FHC e não foram revistas nos governos de Lula. A lei que regulamentou o Fundef (9.424/1996) foi aprovada na véspera do Natal e assim como a $\mathrm{EC} / 14$ foram pouco debatidas e correspondiam às demandas dos organismos multilaterais e aos interesses neoliberais das elites.

O Fundef vigorou por uma década sua função de instituir fundos estaduais e distrital de natureza contábil. Tinha como sistemática de funcionamento a subvinculação de $15 \%$ dos $25 \%$, ou do percentual mínimo previsto nas CE e LOM quando acima do previsto na CF/88, de alguns impostos estaduais e de algumas transferências estaduais e municipais para o ensino fundamental regular que deveria ser distribuído com base no número de matrículas e no valor aluno ano. Cabe destacar que o Fundef não abrangia a educação infantil e o ensino médio, pois tinha como função aumentar o número de trabalhadores escolarizados, conforme determinação dos órgãos internacionais.

Os fundos deveriam ser complementados com recursos da União caso não alcançassem o valor mínimo definido nacionalmente. A União não cumpriu a complementação mantendo o valor aluno-ano baixo, justamente, para não aumentar a complementação aos Fundos. Para a valorização dos profissionais do magistério, os entes deveriam aplicar, no mínimo, 60\% dos recursos do Fundo. Entretanto, como o Fundo não previa recursos novos para a educação, muitos entes não conseguiram valorizar seus profissionais. A lei previa, ainda, o controle e o acompanhamento social dos recursos do Fundo através dos Conselhos criados por lei para esse fim (BRASIL, 1996).

No governo Lula foi criado o Fundo de Manutenção e Desenvolvimento da Educação Básica e de Valorização dos Profissionais da Educação (Fundeb) pela EC 53/2006. Regulamentado pela Lei federal 11.494/2007, está previsto para durar 14 anos e manteve a sistemática de funcionamento do Fundef, com as seguintes mudanças: ampliação do financiamento para etapas e modalidades da educação básica; ampliação da quantidade de impostos estaduais em que o percentual chegaria a 20\% no terceiro ano de implantação do Fundo; complementação da União chegando a 10\% do total de recursos do Fundo; e mais amplitude e representatividade para os Conselhos (MILITÃO, 2011).

A política de desvinculação de recursos da União foi mantida pelo governo Lula, porém a EC 59/2009 determinou o fim progressivo da DRU dos recursos da MDE previstos no artigo 212 da CF/88. Em 2008, foi aprovada a Lei federal 11.738, que regulamenta o Piso Salarial Profissional Nacional (PSPN) que é: “o valor mínimo abaixo do qual não pode ser fixada a remuneração de início de carreira de um determinado profissional, em regime de trabalho de tempo integral" (ABICALIL, 2012, p.71). Além disso, a lei limita a jornada de trabalho com atividades diretas com os alunos em $2 / 3$ da carga horária. Com a finalidade de não cumprirem a lei, 5 governadores (Mato Grosso do Sul, Paraná, Santa Catarina, Rio Grande do Sul e Ceará) apresentaram uma Ação Direta de Inconstitucionalidade (ADI) 4167 ao STF alegando problemas orçamentários para a aplicação da lei, porém, em 2011, com a decisão do STF, a favor da constitucionalidade da lei. 
O processo de privatização da educação intensificou no governo Lula, sobretudo, através da participação cada vez mais direta do movimento Todos pela Educação (TPE) no MEC, na gestão de Fernando Haddad, e no CNE. Criado, em setembro de 2006, por empresários e instituições privadas, a atuação do TPE com o MEC se materializou no Plano de Metas Compromisso Todos pela Educação como eixo articulador estratégico de descentralização do Plano de Desenvolvimento da Escola e a execução dos seus programas e ações através da elaboração do Plano de Ações Articuladas nos estados e municípios.

Apesar da expansão das Instituições de Ensino Superior nos governos de Lula da Silva e Dilma Rousseff, através do programa de Reestruturação e Expansão das Universidades Federais (Reuni), as matrículas no ensino superior privado se expandiram demasiadamente, sobretudo, com o apoio do governo federal através do Fundo de Financiamento Estudantil (Fies), que intensificou a massificação mercantil (SGUISSARDI, 2015).

Os avanços obtidos através da Lei federal 13.005/2014, que regulamentou o novo PNE com 20 metas fundamentais para a organização do Sistema Nacional da Educação, sobretudo, através do seu financiamento tendo como base dos investimentos na educação os $10 \%$ do PIB e a criação do Custo Aluno Qualidade Inicial (CAQi) e do Custo Aluno Qualidade (CAQ), foram frustrados pelo golpe civil jurídico-midiático, empreendido, em 2016. O governo de Michel Temer adotou uma política extremamente neoliberal para a educação no país (SCAFF; GOUVEIA; FERRAZ, 2018) com o apoio do governo dos EUA e o financiamento dos órgãos multilaterais internacionais. O expoente dessa política foi a promulgação da EC 95/2016, cujo objetivo é congelar por 20 anos os investimentos nas áreas sociais, especificamente, educação e saúde. Além da criação das empresas estatais não dependentes, que alimentarão o sistema financeiro privado através da venda da dívida brasileira. Tais medidas inviabilizarão o cumprimento das metas do PNE/2014 (AMARAL, 2017).

Recentemente, em 2019, o Banco Interamericano de Desenvolvimento (BID) lançou um estudo intitulado Melhores gastos para melhores vidas: Como o Brasil e a região podem fazer mais com menos, em que afirma que no Brasil os investimentos em educação aumentaram em demasia e em contrapartida a qualidade diminuiu. Esse "mantra" é defendido também pelo atual governo do presidente Jair Bolsonaro. O banco converge suas análises na opinião, parcialmente equivocada, de que o Brasil aplica 6\% do seu PIB na educação, ficando acima da média da Organização para a Cooperação e Desenvolvimento Econômico (OCDE) (organização internacional composta por 36 países ricos) e tem um rendimento pífio na avaliação internacional estandardizada do Programa Internacional de Avaliação de Estudantes (Pisa), ou Programme for International Student Assessment.

O equívoco reside no fato de comparar o Brasil com países ricos e com enormes disparidades econômicas e demográficas. Além disso, embora aplique 6\% do PIB na educação (pública e privada, digase de passagem), o Brasil é um dos países da OCDE com o menor custo-aluno. O valor apresentado pelo governo brasileiro é questionável, porque está inflado de despesas alheias à educação, como o gasto com inativos da educação, hospitais universitários, pesquisas de áreas alheias à educação, entre outras. Ainda, a avaliação do Pisa centra-se na avaliação dos estudantes, deixando de fora vários elementos que poderiam 
contribuir para avaliar a qualidade da educação, como as políticas educacionais adotadas pelos países e sua gestão democrática, as condições das unidades escolares, a qualificação e a remuneração docente, entre outras.

Os esforços dos organismos internacionais em tentar comprovar os gastos excessivos do Brasil em educação advêm, em grande medida, da orientação de que o país cumpra com os compromissos da dívida pública. Um dado relevante é que, em 2018, o governo gastou $\mathrm{R} \$ 1,1$ trilhão com juros e amortizações da dívida de um orçamento que totalizou R \$2,6 trilhões. É importante destacar que a dívida brasileira é de mais de $\mathrm{R} \$ 5,5$ trilhões (parte dela, provavelmente, fraudulenta, como concluiu a Comissão Parlamentar de Inquérito do Congresso Nacional instaurada na década de 1980), segundo dados da Secretaria do Tesouro Nacional.

\section{Aspectos conclusivos}

É necessário compreender os meandros do financiamento da educação brasileira, sobretudo, para não cair no lugar-comum dos discursos que tentam cristalizar um senso comum de classe ao afirmar que o país gasta muito com educação. Mesmo entendendo a complexidade da luta de classes no atual panorama político, econômico, social e histórico, é necessário atuar com base naquilo que Coutinho (1992) designou de "reformismo revolucionário" como caminho mais adequado para a luta pelo socialismo no Brasil. Dessa forma é fundamental compreender a realidade da função e das finalidades dos recursos da educação e tensionar os governos para que os aplique devidamente em sua finalidade.

\section{Referências}

ABICALIL, C. A. Piso Salarial: constitucional, legítimo, fundamental. Retratos da Escola, Brasília, v. 2, n. 2/3, 2012.

AMARAL, N. C. PEC 241/55: a "morte" do PNE (2014-2024) e o poder de diminuição dos recursos educacionais. Revista Brasileira de Política e Administração da Educação, Goiânia, ANPAE: S. 1., v. 32, n. 3, p. 653-673, dez. 2016.

BALEEIRO, A. O Supremo Tribunal Federal, esse outro desconhecido. Rio de Janeiro, Forense, 1968.

BIB. Banco Interamericano de Desenvolvimento. Melhores gastos para melhores vidas: Como o Brasil e a região podem fazer mais com menos. Disponível em: https://flagships.iadb.org/pt/DIA2018/gastopublico-no-brasil . Acesso em: 12 jun. 2019.

BRASIL. Ministério da Educação. Plano Decenal de Educação para Todos. Brasília, 1993.

BRASIL. Lei 9.424, de 24 de dezembro de 1996. Dispõe sobre o Fundo de Manutenção e

Desenvolvimento do Ensino Fundamental e de Valorização do Magistério, na forma prevista no artigo 60 $\int 7^{\circ}$, do Ato das Disposições Constitucionais Transitórias, e dá outras providências. Brasília: Diário Oficial da União, Brasília, 26 dez. 1996.

COUTINHO, C. N. Democracia e socialismo. Questões de princípio e contexto brasileiro. São Paulo: Cortez, 1992.

A época neoliberal: revolução passiva ou contra-reforma? Revista Novos Rumos, Marília, v. 49, n. 1, 2012. Disponível em 
http://www2.marilia.unesp.br/revistas/index.php/novosrumos/article/view/2383/1943 acesso 29/09/2019.

CUNHA, L. A. O legado da ditadura para a educação brasileira. Educação \& Sociedade, Campinas, v. 35, n. 127, 2014 Disponível em. http://www.scielo.br/pdf/es/v35n127/v35n127a02.pdf. Acesso 29/09/2019.

CURY, Carlos Roberto Jamil. Financiamento da Educação Brasileira: do subsídio literário ao FUNDEB. Educ. Real. [online]. 2018, vol.43, n.4 [cited 2019-09-29], pp.1217-1252. Available from:

$<$ http://www.scielo.br/scielo.php?script=sci_arttext\&pid=S2175-

62362018000401217\&lng=en\&nrm=iso >. ISSN 0100-3143. http://dx.doi.org/10.1590/2175623684862.

DAVIES, N. O salário-educação: fragilidades e incoerências. Revista Brasileira de Estudos Pedagógicos. Brasília, v. 89, n. $223,2009$.

ENGELS, F. A situação da classe trabalhadora na Inglaterra. São Paulo: Boitempo, 2010.

GRAMSCI, A. Maquiavel, a Política e o Estado Moderno. Tradução de Luiz Mário Gazzane. 6. ed. Rio de Janeiro: Civilização Brasileira, 1988. (Série Política e Perspectiva do Homem, v. 35.

VIEIRA, S. L. A educação nas constituições brasileiras: texto e contexto. Revista Brasileira de Estudos pedagógicos. Brasilia, v. 88, n. 219, 2007.

MARX, K. Manuscritos Econômicos-Filosóficos. 1844. Disponível em:

<https://www.marxists.org/portugues/marx/1844/manuscritos/index.htm>. Acesso em: 12 jun. 2019.

MELCHIOR, J. C. A. O financiamento da educação no Brasil. São Paulo: EPU, 1987.

MILITÃO, S. C. N. FUNDEB: MAIS DO MESMO? Nuances: estudos sobre Educação, Presidente Prudente, v. 18, n. 19, p. 124-135, 2011. Disponível em:

http://revista.fct.unesp.br/index.php/Nuances/article/view/351/386. Acesso, 29/09/2019.

MUNHOZ, S. J. Ecos da emergência da Guerra Fria no Brasil (1947-1953). Diálogos, Maringá, v. 6, n. 1, p. 41-59, 2002.

POULANTZAS, N. O Estado, o poder, o socialismo. Rio de Janeiro: Graal, 1980.

RICARDO, A. (Org.). A Dialética do Trabalho II - Escritos de Marx e Engels. São Paulo. Expressão Popular, 2013

SANTOS, M. H. C. dos. Poder, intelectuais e contra-poder. In: SANTOS, M. H. C. dos (Org.). Pombal revisitado. v. 1, Lisboa: Editorial Estampa, 1982. p. 122-129.

SGUISSARDI, Valdemar. Educação Superior no Brasil. Democratização ou massificação mercantil?. Educ. Soc. [online]. 2015, vol.36, n.133 [cited 2019-09-30], pp.867-889. Available from:

$<$ http://www.scielo.br/scielo.php?script=sci_arttext\&pid=S0101-

73302015000400867\&lng=en\&nrm=iso >. ISSN 0101-7330. http://dx.doi.org/10.1590/ES010173302015155688 .

WEBER, M. Economia e sociedade: fundamentos da sociologia compreensiva (Vol. 2). R. Barbosa, \& KE Barbosa, 1999.

\section{Notas:}

1 Professor Adjunto da Faculdade de Educação da Universidade Federal do Rio de Janeiro. Pós-doutor em educação pela UFG. Doutor em educação pela USP. Mestre em educação, cultura e comunicação pela UERJ-FEBF. Pedagogo pela UERJ-FEBF. ORCID: https://orcid.org/0000-0001-5756-3654 Email: f.asouza@yahoo.com.br 